\title{
A NEW GENUS AND A NEW SPECIES OF THE FAMILY PYGMEPHORIDAE (ACARI: HETEROSTIGMATA) FROM WESTERN SIBERIA, RUSSIA
}

\author{
Alexander A. Khaustov \\ X-BIO Institute, Tyumen State University, Tyumen, Russia \\ e-mail: alkhaustov@mail.ru
}

ABSTRACT: Phoretic and non-phoretic females of a new genus and a new species of pygmephorid mites_Bochkovlaster variabilis gen.n. and sp.n. (Acari: Prostigmata: Pygmephoridae), collected from rotting birch trees-are described from Western Siberia, Russia. An updated key to the genera of Pygmephoridae is provided.

KEY WORDS: Pygmephoroidea, systematics, new taxa, female dimorphism, key.

DOI: 10.21684/0132-8077-2019-27-2-193-208

\section{INTRODUCTION}

Pygmephoridae - a cosmopolitan family of mites - is the second largest in the superfamily Pygmephoroidea. It includes 32 described genera and more than 300 species (Khaustov et al. 2019b). All pygmephorid mites are probably fungivorous (Kaliszewski et al. 1995). Pygmephorid mites inhabit soil, forest litter and rotting matter. Many pygmephorid species are associated with various insects, utilizing them for phoresy. Representatives of the genus Pygmephorus are associated with small mammals (Kaliszewski et al. 1995; Khaustov et al. 2019b). Some pygmephorid genera are characterized by the presence of two different forms of females: phoretic and non-phoretic, which differ considerably in terms of morphology. The phenomenon of female dimorphism is well described for the genus Pediculaster Vitzthum (see Camerik et al. 2006). Dimorphic females are also known in the genus Pediculitopsis Mahunka, 1970, which is poorly described. Most likely, female dimorphism is also present in the genus Metasiteroptes Cross, 1965. This statement is based on the fact that the mites of the genus Brasilopsis Mahunka, 1975 are very similar to Metasiteroptes, differing only in the fused tibia and tarsus I, as well as in the shape of seta $d$ of femur I. The above differences are typical of phoretic and non-phoretic females of a closely related genus, Pediculaster.

During the study of heterostigmatic mites in Western Siberia, Russia, I found a new remarkable monotypic genus of Pygmephoridae, which is also characterized by female dimorphism. An updated key to the genera of Pygmephoridae is also provided.

\section{MATERIALS AND METHODS}

The mites were extracted from samples of rotting wood and bark of birch trees using Berlese funnels. Most of the collected mites were cleared in lactic acid and mounted in Hoyer's medium. The terminology used in the descriptions of the idiosoma and the legs follows that of Lindquist (1986); the nomenclature of subcapitular setae and the designation of cheliceral setae follow those of Grandjean $(1944,1947)$, respectively. The systematics of Pygmephoroidea follows that of Khaustov (2004, 2008). All measurements are given in micrometers $(\mu \mathrm{m})$ for the holotype and five paratypes (in parentheses). In the description of leg chaetotaxy, the number of solenidia is given in parentheses. Mite morphology was studied using a Carl Zeiss AxioImager A2 (Carl Zeiss, Germany) compound microscope with phase contrast and differential interference contrast (DIC) objectives. Photomicrographs were taken with an AxioCam 506 color (Carl Zeiss, Germany) digital camera. For SEM microscopy, alcohol-preserved mites were dried in a freeze-drying device JFD 320 (JEOL, Japan), coated with gold, and scanned with the aid of a JEOL JSM-6510LV SEM microscope; several alive specimens were scanned without coating.

\section{SYSTEMATICS}

Family Pygmephoridae Cross, 1965

Genus Bochkovlaster gen.n.

Type species: Bochkovlaster variabilis sp.n.

Description. Phoretic female. Body weakly sclerotized, oval. Gnathosomal capsule of about equal length and width, prognathous, dorsally with two pairs of cheliceral setae (cha, chb); postpalpal 
setae absent; palps prominent, with two pairs of setae ( $d F e, d G e$ ); tibial claw distinct; palpal solenidion ( $(s o l)$ well developed, accessory setigenous structure (ass) large, mushroom-like. Palp tibiotarsus with tiny distal eupathidium. Palpal femorogenu with unusual oval dorsodistal projection $(d p)$ (Figs. 10A, 11B). Subcapitular setae $(\mathrm{m})$ present. A pair of long and thin trachea-like structures present inside gnathosoma. Pharyngeal pumps tripartite, situated on a very long and thin oesophagus, which rolled into a ball between pharyngeal pumps 1 and 2 (Fig. 10E); all pharyngeal pumps weakly striated; pump 1 bow-shaped, very far separated from pump 2; pumps 2 and 3 oval, situated close to each other. Prodorsum with three pairs of setae $\left(v_{1}, v_{2}, s c_{2}\right)$, one pair of clavate trichobothria $\left(s c_{1}\right)$ and one pair of small oval stigmata; prodorsal shield indistinctly divided into two poorly sclerotized sclerites. Tracheal trunks well developed, long (Fig. 10E). Tergite $C$ with two pairs of setae $\left(c_{1}\right.$, $\left.c_{2}\right)$; tergite $\mathrm{D}$ with one pair of setae $(d)$; tergite $\mathrm{EF}$ with two pairs of setae $(e, f)$; tergite $\mathrm{H}$ with one pair of setae $\left(h_{1}\right)$ and one pair of oval cupules $i h$. Coxal fields I with three pairs of setae $(1 a, 1 b, 1 c)$, setae $1 b$ not modified; coxal fields II with two pairs of setae $(2 a, 2 c)$; coxal fields III with three pairs of setae $(3 a, 3 b, 3 c)$; coxal fields IV with three pairs of setae $(4 a, 4 b, 4 c)$. Pseudanal segment with one pair of setae $\left(p s_{2}\right)$; alveolar pits of setae $p s_{1}$ present. Apodemes 1 (ap1) well developed; apodemes 2 (ap2) well developed, joined with well-developed prosternal apodeme (appr); sejugal apodeme not developed; secondary transverse apodeme absent; apodemes 3 (ap3) well developed, fused with welldeveloped poststernal apodeme (appo); apodemes 4 (ap4) well developed, fused with appo; apodemes 5 absent. Posterior margin of posterior sternal plate with median lobe. Anterior genital sclerite (ags) very small; posterior genital sclerite not evident. Leg I 4-segmented, with cylyndrical tibiotarsus. Tarsal claw simple. Unguinal setae not modified; seta $u$ ' absent (usually) (Fig. 3A) or present (Fig. 3B). Tibiotarsus without pinnaculum. Seta $d$ of femur I long, hook-shaped (Fig. 11C). Seta $k$ smooth, eupathid-like. Legs II and III each with one pair of slightly thickened hooked claws and small elongate empodium; tarsal claws of leg IV not modified, hooked, empodium wider than on tarsi II and III. Solenidia on tibiae II-IV erect (Fig. 11D). Femora III and IV divided into basi- and telofemur; basi- and telofemur IV articulated. Seta $p$ ' of tibiotarsus I simple, not eupathid-like. Leg setation: leg I: $\operatorname{Tr} 1\left(v^{\prime}\right), \operatorname{Fe} 4\left(d, l^{\prime}, l^{\prime}, v^{\prime \prime}\right)$, Ge $4\left(l^{\prime}\right.$, $\left.l^{\prime \prime}, v^{\prime}, v^{\prime \prime}\right)$, TiTa 19(4) (d, l', l", $v^{\prime}, v^{\prime \prime}, k, t c^{\prime}, t c^{\prime \prime}, p^{\prime}$, $p^{\prime \prime}, f t^{\prime}, f t^{\prime \prime}, p v^{\prime}, p v^{\prime \prime}, p l^{\prime}, p l l^{\prime \prime}, s, u^{\prime}, u^{\prime \prime}, \omega_{1}, \omega_{2}, \varphi_{1}$, $\left.\varphi_{2}\right)$; leg III: Tr $1\left(v^{\prime}\right), \operatorname{Fe} 3\left(d, l^{\prime}, v^{\prime \prime}\right), \operatorname{Ge} 3\left(l^{\prime}, v^{\prime}, l^{\prime \prime}\right)$, Ti 4(1) (d, l', v', v", $\varphi$ ), Ta 6(1) (tc', tc", $p l l^{\prime \prime}, p v^{\prime}$, $\left.p v^{\prime \prime}, u^{\prime}, \omega\right)$; leg III: Tr $1\left(v^{\prime}\right), \operatorname{Fe} 2\left(d, v^{\prime}\right), \operatorname{Ge} 2\left(l^{\prime}\right.$, $\left.v^{\prime}\right)$, Ti 4(1) (d, l', v', $\left.v^{\prime \prime}, \varphi\right)$, Тa 6 (tc', tc", $p l^{\prime \prime}, p v^{\prime}$, $\left.p v^{\prime \prime}, u^{\prime}\right)$; leg IV: $\operatorname{Tr} 1\left(v^{\prime}\right), \operatorname{Fe} 2\left(d, v^{\prime}\right), \mathrm{Ge} 1\left(v^{\prime}\right)$, Ti 4(1) (d, l', v', $\left.v^{\prime \prime}, \varphi\right)$, Тa 6 ( $p l l^{\prime \prime}, t c^{\prime}, t c^{\prime \prime}, u$ ', $\left.p v^{\prime}, p v^{\prime \prime}\right)$.

Non-phoretic female. In general, very similar to phoretic female, except for the following characters: prodorsal shield not separated into two sclerites, with a dorsal median prodorsal apodeme; main tracheal trunks not visible (Fig. 10F); palpal femorogenu without dorsodistal projection; tibia and tarsus I separated; seta $p$ ' of tibiotarsus I eupathid-like; seta $d$ of femur I not modified; tarsi II and III with seta $u$ "; claws on legs II and III simple, hooked.

Male and Larva unknown.

Species included. The genus Bochkovlaster includes one species, $B$. variabilis sp. n.

Distribution and habitat. $B$. variabilis sp.n. inhabits rotting wood and bark of birch trees in Western Siberia. Phoretic hosts unknown.

Differential diagnosis. The phoretic female of the genus Bochkovlaster is most similar to Apediculaster Rahiminejad and Hajiqanbar, 2016 in: the absence of cupules $i a$ and setae $h_{2}, p s_{1}, p s_{3}$; divided prodorsal shield; long hooked seta $d$ of femur I; and oval body shape. It can be distinguished from Apediculaster by: the presence of three pairs of setae on the prodorsum (two pairs of setae on prodorsum in Apediculaster); simple claw on tibiotarsus I (the claw is thick and strongly curved in Apediculaster); and simple, unmodified unguinal setae on tibiotarsus I (modified, forms a structure opposing the tarsal claw in Apediculaster). Non-phoretic female of Bochkovlaster is most similar to Metasiteroptes Cross, 1965 in the absence of setae $h_{2}$ and $p s_{3}$. The former differs from the latter in: the oval body shape (body shape fusiform in Metasiteroptes); setae $p s_{1}$ being absent (present in Metasiteroptes); genua II and III having three and two setae, respectively (genua II and III each have only one seta in Metasiteroptes).

Etymology. The name of the new genus is a combination of two words: Bochkov-family name of a Russian acarologist; and laster - the ending of Apediculaster, the closest related genus. The new genus is named after a prominent acarologist, Andrei Bochkov, who passed away too soon. 
New Pygmephoridae from Western Siberia
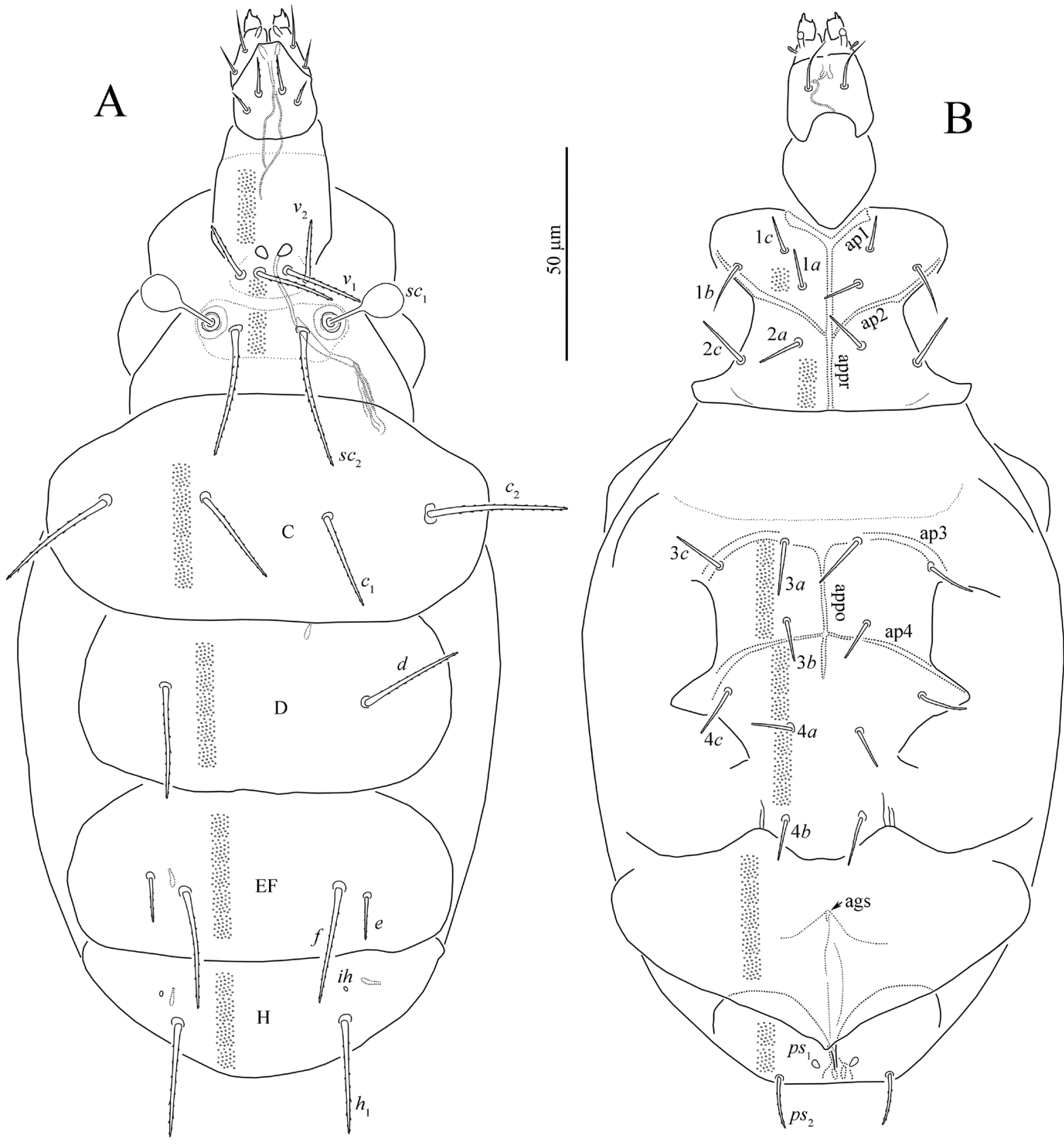

Fig. 1. Bochkovlaster variabilis gen. n. and sp. n., phoretic female: A—dorsum of the body, B-venter of the body. Legs omitted.

\section{Bochkovlaster variabilis sp. $\mathrm{n}$.}

(Figs. 1-12)

Description. Phoretic female (Figs. 1-5, 10AE, 11, 12F). Length of idiosoma 220 (215-230), width 110 (105-115).

Idiosomal dorsum (Figs. 1A, 5A, 10A, C, 11A). Stigmata located just anteriad setae $v_{1}$ and close to each other (Fig. 10A). All dorsal sclerites with numerous very small dimples. All dorsal setae blunt-ended and weakly barbed. Trichoboth- ria with short stem, clavate, smooth, with rounded apex. Tergite D unusually narrow, not covering lateral parts of idiosoma. Lengths of dorsal setae: $v_{1} 19$ (16-21), $v_{2} 15$ (13-15), sc 32 (31-34), $c_{1} 24$ (20-25), c 33 (31-36), d 26 (24-28), e 10 (11-12), $f 27$ (26-29), $h_{1} 27$ (23-27). Distances between setae: $v_{1}-v_{1} 7(7-8), v_{2}-v_{2} 16(16-19), s c_{2}-s c_{2} 16$ (16-19), $c_{1}-c_{1} 29$ (26-30), $c_{1}-c_{2} 23(22-25)$, $d-d 47$ (40-47), e-f 7 (6-9), f-f 36 (29-36), $h_{1}-$ $h_{1} 39$ (33-39). 

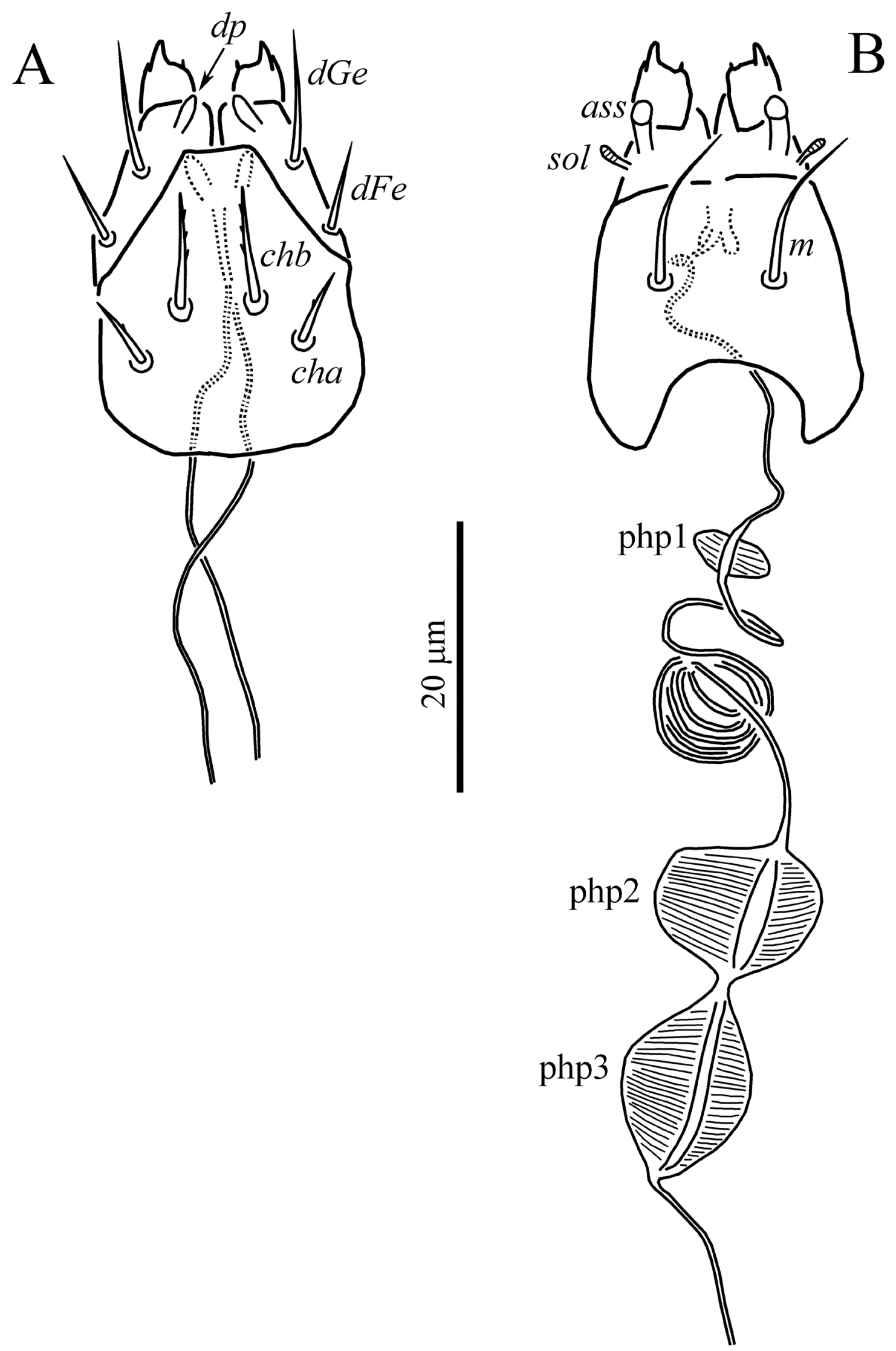

Fig. 2. Bochkovlaster variabilis gen.n. and sp.n., phoretic female: A—gnathosoma in dorsal view, B-gnathosoma and pharyngeal pumps in ventral view. 


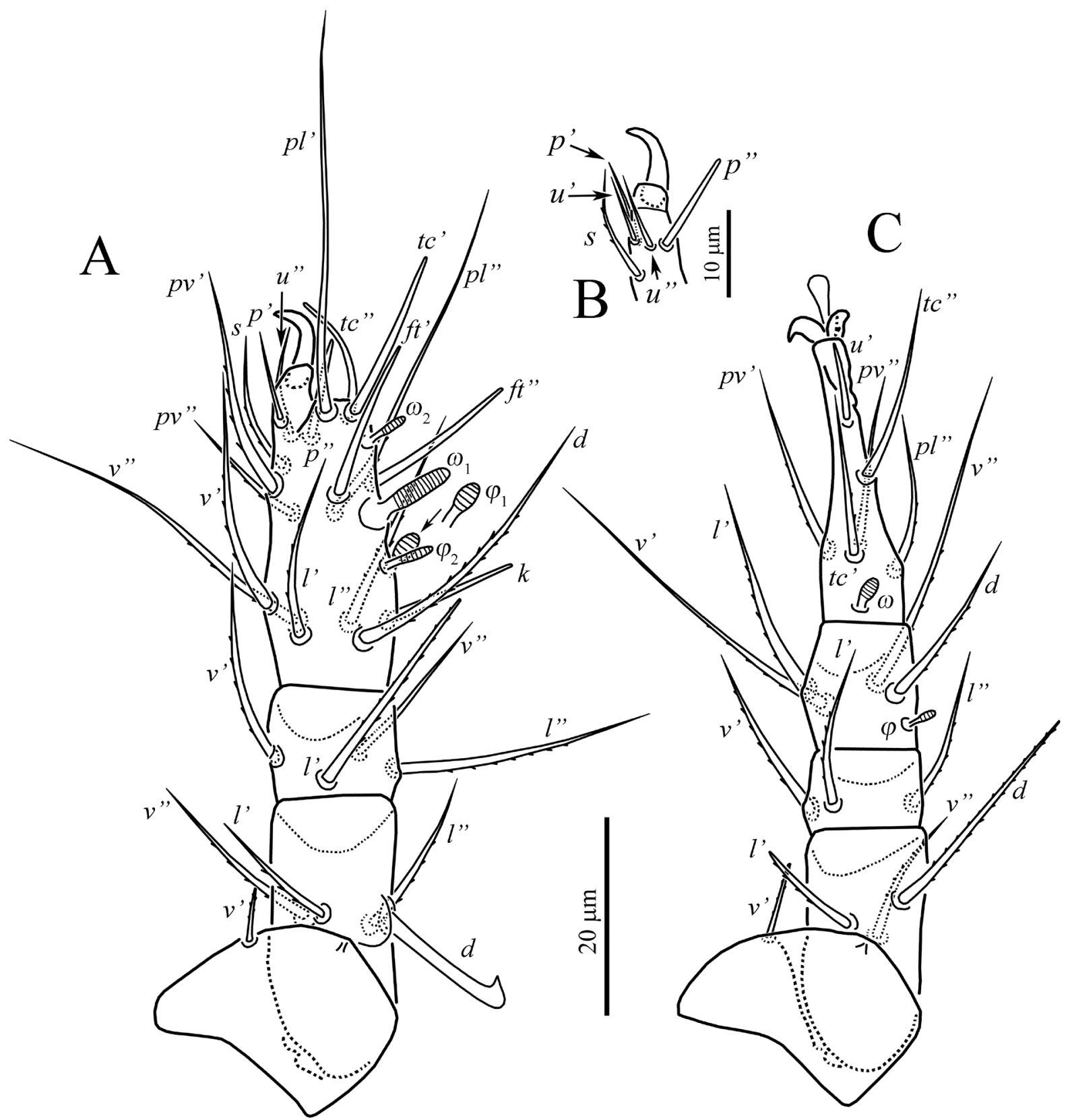

Fig. 3. Bochkovlaster variabilis gen.n. and sp.n., phoretic female: A—right leg I in dorsal view, B-distal part of tibiotarsus I of paratype with seta $u$ ' in ventral view, C-right leg II in dorsal view.

Idiosomal venter (Figs. 1B, 5 B, 10B, D). All ventral plates with numerous small dimples. All ventral setae weakly barbed; setae $1 b$ pointed, other ventral setae blunt-ended. Posterior margin of aggenital plate angled. Lengths of ventral setae: $1 a 9$ (9-10), $1 b 13$ (11-14), 1c 9 (8-9), $2 a 11$ (10-11), 2c 13 (11-13), $3 a 13$ (12-14), $3 b 10$ (911), 3c 12 (11-13), $4 a 10$ (9-11), $4 b 12$ (11-13), $4 c 11$ (11-14), $\mathrm{ps}_{2} 13$ (13-15).

Gnathosoma (Figs. 2, 11B, 12F). Length of gnathosoma 23 (22-24), width 20 (20-24). Dorsal median apodeme absent. Setae cha and chb weakly blunt-ended and barbed (Fig. 12F), other gnathosomal setae smooth and pointed. Alveolal pits $n$ absent. Lengths of gnathosomal setae: $m 13$ (12-14), cha 6 (5-7), chb 8 (8-10). Pharyngeal pumps as in Fig. 2B.

Legs (Figs. 3, 4, 11C, D). Leg I (Figs. 3A, 11C). Lengths of solenidia $\omega_{1} 8$ (8-9), $\omega_{2} 5$ (5-6), $\varphi_{1} 6$ (5-6), $\varphi_{2} 6(6)$; solenidion $\omega_{1}$ digitiform, solenidion $\varphi_{1}$ clavate, solenidia $\omega_{2}$ and $\varphi_{2}$ baculiform. Setae $d$ of femur, $k,(u), p l^{\prime}, p$ ' and eupathidia $(f t),(t c), p$ " 

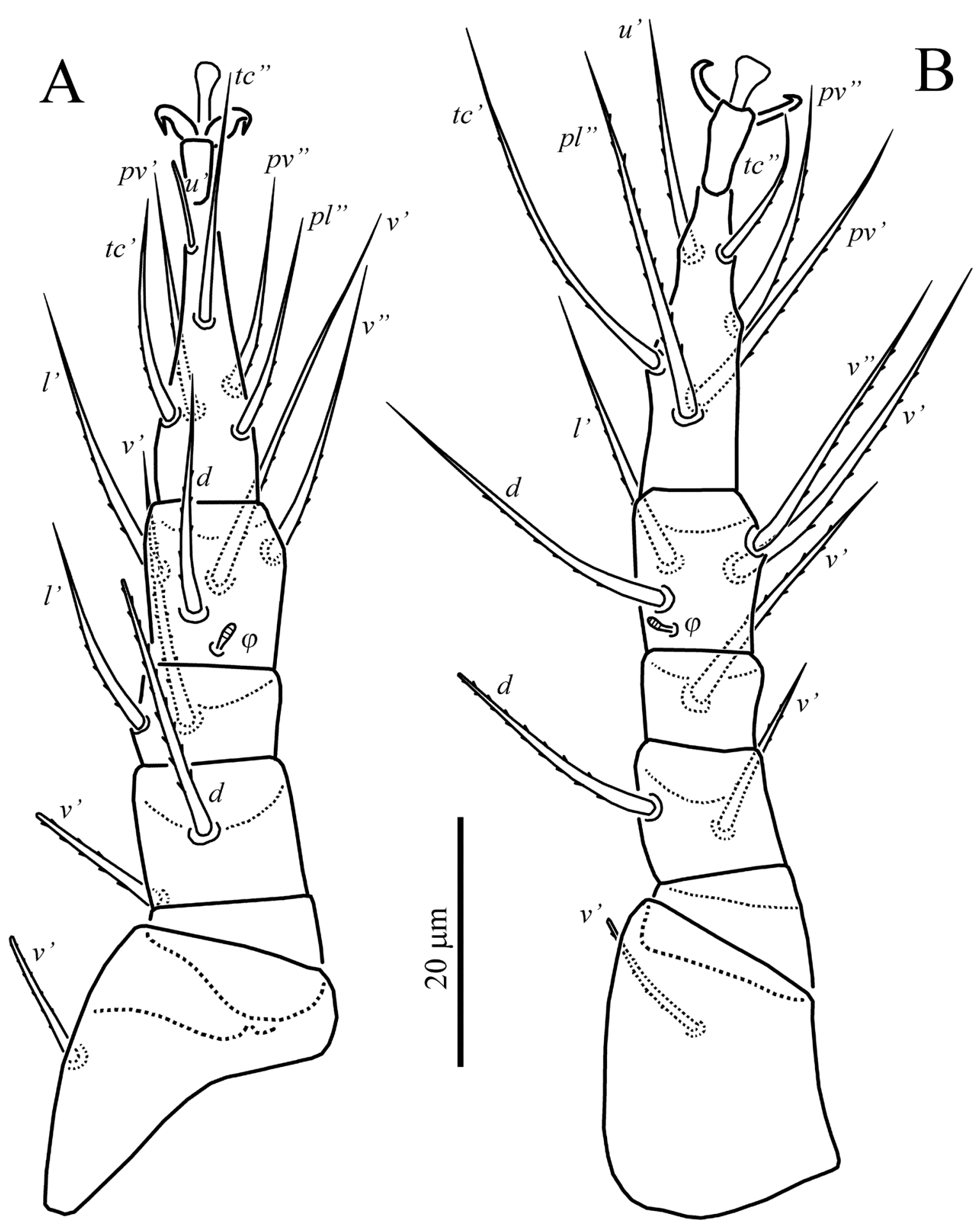

Fig. 4. Bochkovlaster variabilis gen.n. and sp.n., phoretic female: A—right leg III in dorsal view, B-right leg IV in dorsal view.

of tibiotarsus smooth, other setae weakly barbed; setae $v^{\prime}$ of trochanter, $l$ ' of genu, $k$ and eupathidia of tibiotarsus blunt-ended, other leg setae pointed; seta $u$ ' present or absent, sometimes asymmetrically present and absent on the left and right legs of the same specimen. Leg II (Fig. 3B). Solenidion $\omega 6$ (5-6) digitiform, solenidion $\varphi$ 3 (3-4) weakly clavate. Seta $t c$ " and $u$ ' of tarsus smooth, other leg setae weakly barbed; setae $v$ ' of trochanter, $d$, l' of femur, and $u$ ' of tarsus blunt-ended, other leg setae 


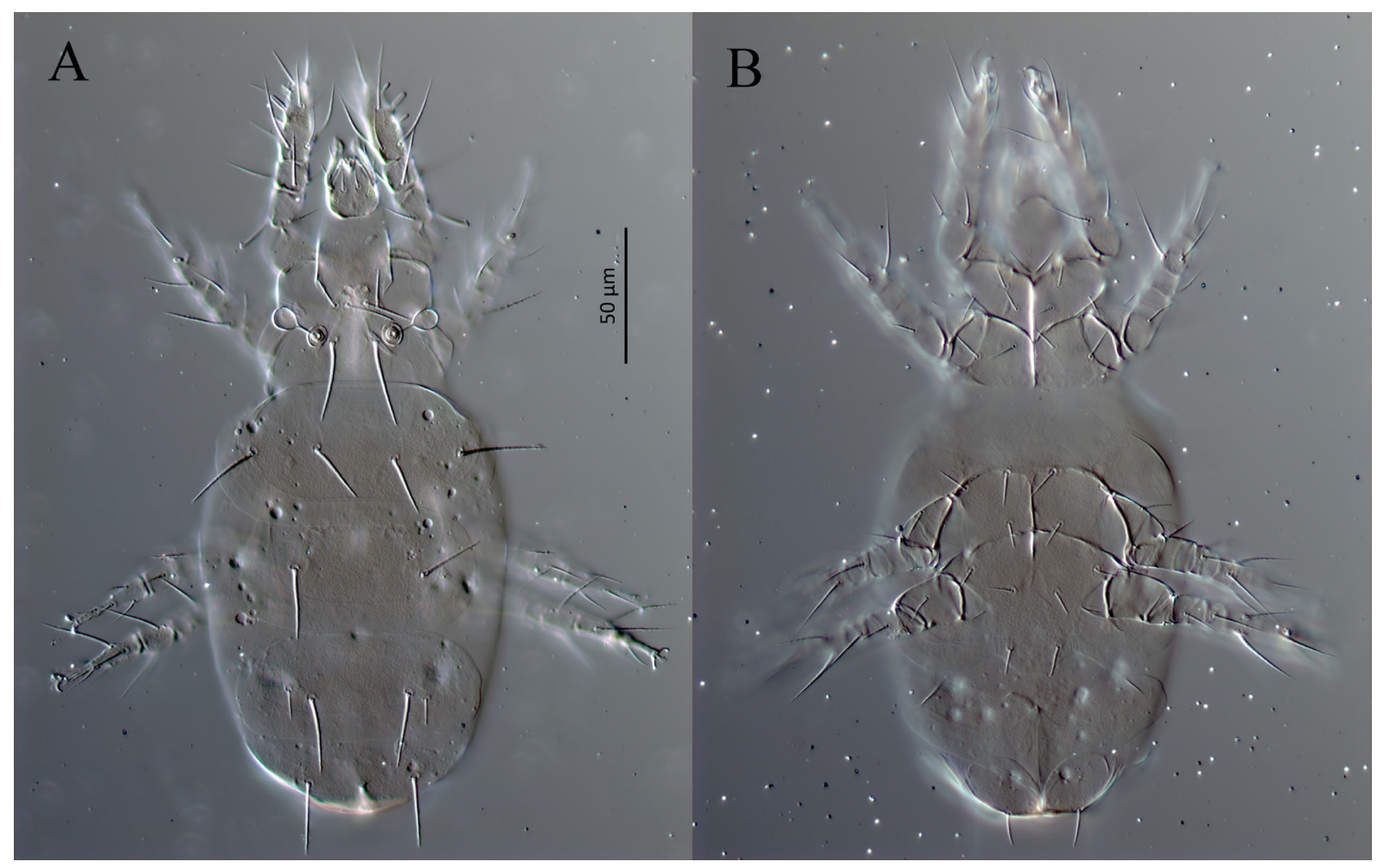

Fig. 5. DIC micrographs of Bochkovlaster variabilis gen.n. and sp.n., phoretic female: A—general view dorsally, B-general view ventrally.

pointed. Leg III (Figs. 4A, 11D). Solenidion $\varphi 3$ (3-4) weakly clavate. Setae $t c$ " and $u$ ' of tarsus smooth, other leg setae weakly barbed; setae $v^{\prime}$ of trochanter, $d$, $v^{\prime}$ of femur and $u^{\prime}$ of tarsus bluntended, other leg setae pointed. Leg IV (Fig. 4B). Solenidion $\varphi$ 2-3 weakly clavate. All leg setae weakly barbed. Setae $v$ ' of trochanter and $d$ of femur blunt-ended, other leg setae pointed.

Non-phoretic female (Figs. 6-9, 10F, 12A-E). Length of idiosoma 180-245, width 90-125.

Idiosomal dorsum (Figs. 6A, 12A, B). Prodorsum with dorsal median prodorsal apodeme, located between bases of trichobothria. Dorsal setae and dimples as in phoretic female. Lengths of dorsal setae: $v_{1} 15-18, v_{2} 11-13, s c_{2} 28-30, c_{1}$ 18-24, c 2 26-35, d 22-27, e 8-12, f 22-29, $h_{1}$ 21-27. Distances between setae: $v_{1}-v_{1} 7-8, v_{2}-v_{2}$ 17-20, $s c_{2}-s c_{2} 18-22, c_{1}-c_{1} 22-36, c_{1}-c_{2} 21-27$, $d-d 37-51, e-f 8-9, f-f 31-40, h_{1}-h_{1} 37-41$.

Idiosomal venter (Figs. 6B, 12C, D). Setae and dimples as in phoretic female. Lengths of ventral setae: $1 a$ 7-10, $1 b$ 11-13,1c 8-10, 2a 10-13, 2c 10-13, 3a 10-12, 3b 8-11, 3c 10-13, 4a 8-11, 4b $10-14,4 c 10-13, p_{2} 12-14$.

Gnathosoma (Figs. 7, 12E). Gnathosoma as in phoretic female, except for the absence of dorsal projection on palpal femorogenu. Length of gnatho- soma 22-24, width 20-23. Lengths of gnathosomal setae: $m$ 13-14, cha 6-7, chb 7-10.

Legs (Figs. 8, 9). Leg I (Fig. 8A). Lengths of solenidia $\left.\omega_{1} 8-9, \omega_{2} 4-5, \varphi_{1} 5-6, \varphi_{2} 5-6\right)$; solenidion $\omega_{1}$ digitiform, solenidion $\varphi_{1}$ clavate, solenidia $\omega_{2}$ and $\varphi_{2}$ weakly clavate. Setae $k$ of genu, $p l$, and eupathidia $(f t),(t c),(p)$ of tarsus smooth, other setae weakly barbed; setae $v$ ' of trochanter, $d, l$ ' of femur, $l$ ' of genu, $k$ and eupathidia of tarsus bluntended, other leg setae pointed. Leg II (Fig. 8B). Solenidion $\omega$ 5-6 digitiform, solenidion $\varphi$ 3-4 weakly clavate. All leg setae weakly barbed; setae $v$ ' of trochanter and $d, l$ ' of femur blunt-ended; other leg setae pointed. Leg III (Fig. 9A). Solenidion $\varphi$ 3-4 weakly clavate. All leg setae weakly barbed; setae $v^{\prime}$ of trochanter and $d, v^{\prime}$ of femur blunt-ended; other leg setae pointed. Leg IV (Fig. 9B). Solenidion $\varphi$ 2-3 weakly clavate. All leg setae weakly barbed. Setae $v$ ' of trochanter and $d$ of femur blunt-ended, other leg setae pointed.

Type material. Phoretic female holotype, slide AK100719: Russia, Tyumen Region, Tyumen, Zatyumenskiy Park, $57^{\circ} 09^{\prime} 56.2^{\prime \prime} \mathrm{N}, 65^{\circ} 26^{\prime} 48.8^{\prime \prime} \mathrm{E}$, in the rotting bark of birch, 10.VII.2019, coll. A.A. Khaustov; paratypes: 7 phoretic females, 7 nonphoretic females, same data; 6 phoretic, 6 nonphoretic, 7.VII.2019, same locality; 27 non-phoretic, 

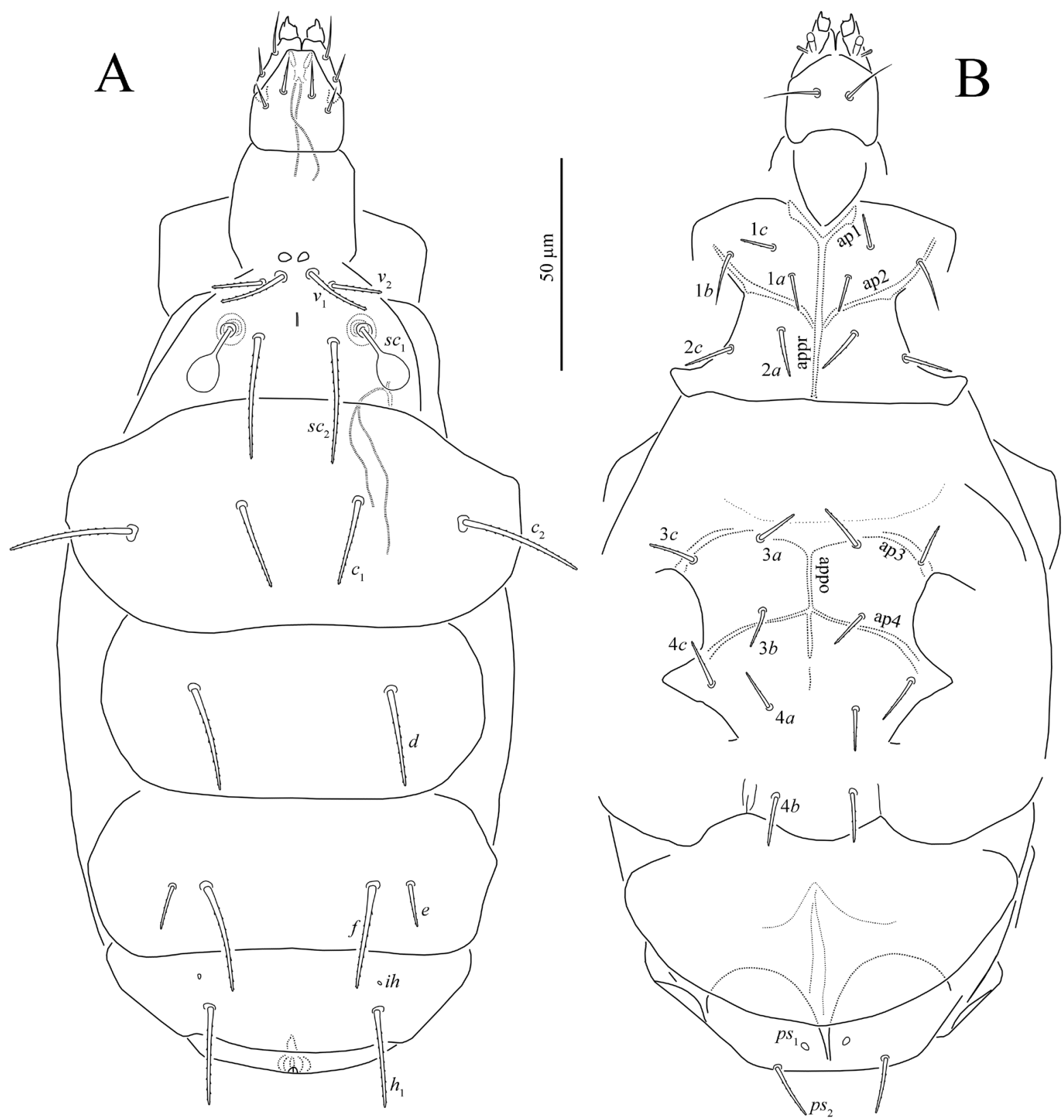

Fig. 6. Bochkovlaster variabilis gen. n. and sp.n., non-phoretic female: A — dorsum of the body, B — venter of the body. Legs omitted.

same locality, in a rotting birch $\log$, 29.IX.2019; 5 non-phoretic, Russia, Kurgan Region, Zverinogolovskiy District, vicinity of settlement Ukrainets, $54^{\circ} 24^{\prime} 11.6^{\prime \prime} \mathrm{N} 64^{\circ} 49^{\prime} 08.6^{\prime \prime} \mathrm{E}$, in a rotting birch $\log$, 20.IX.2019, coll. A.A. Khaustov.

Type deposition. The holotype and five paratypes are deposited in the acarological collection of the Zoological Institute of RAS, St. Petersburg,
Russia, other paratypes are deposited in the mite collection of the Tyumen State University Museum of Zoology, Tyumen, Russia (TSUMZ).

Etymology. The name of the new species is derived from Latin variabilis, meaning variable and refers to the unusual variability in the number of unguinal setae on tibiotarsus I in the phoretic female. 

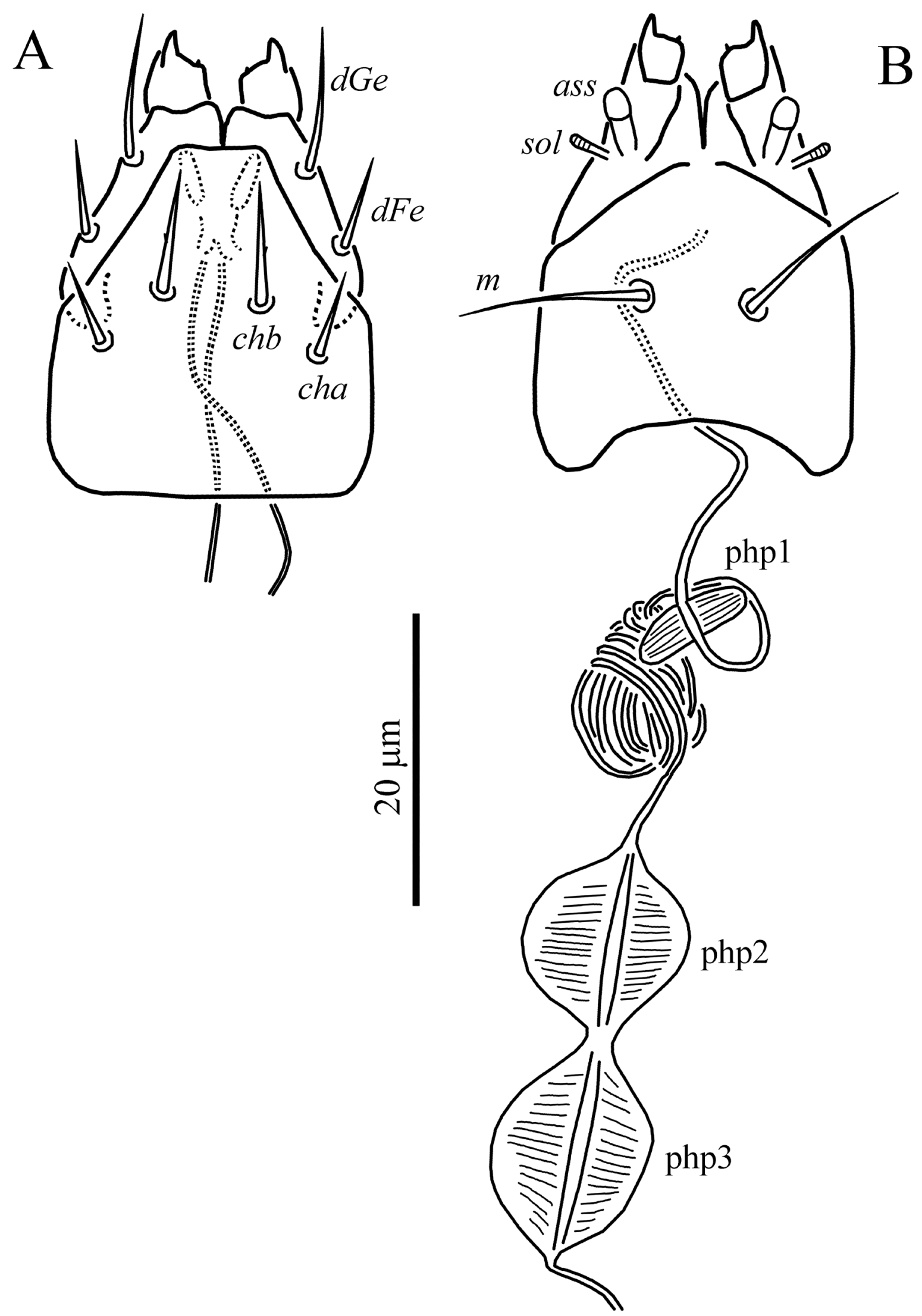

Fig. 7. Bochkovlaster variabilis gen. n. and sp.n., non-phoretic female: A-gnathosoma in dorsal view, B-gnathosoma and pharyngeal pumps in ventral view. 


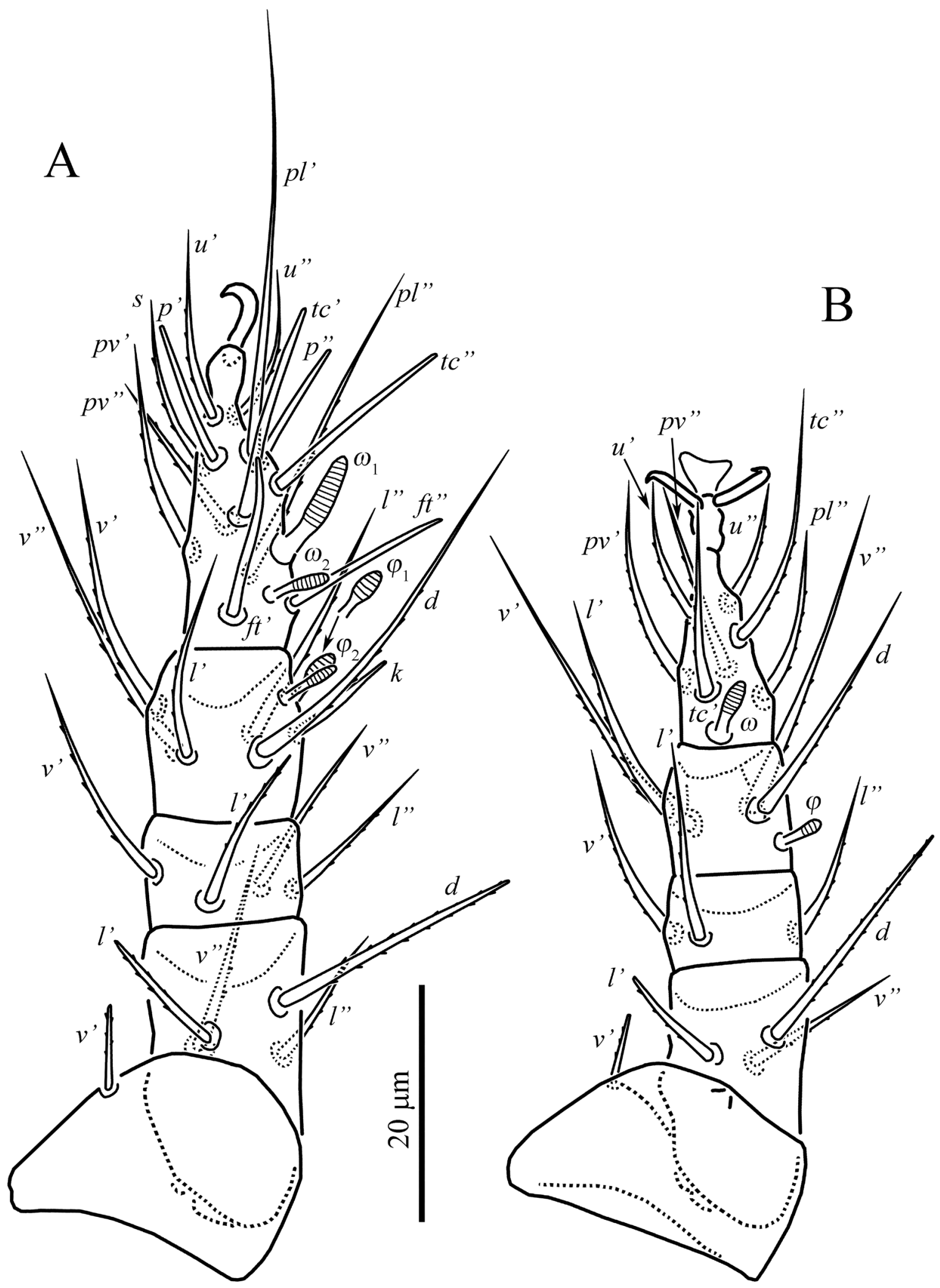

Fig. 8. Bochkovlaster variabilis gen.n. and sp.n., non-phoretic female: A—right leg I in dorsal view, B-right leg II in dorsal view. 


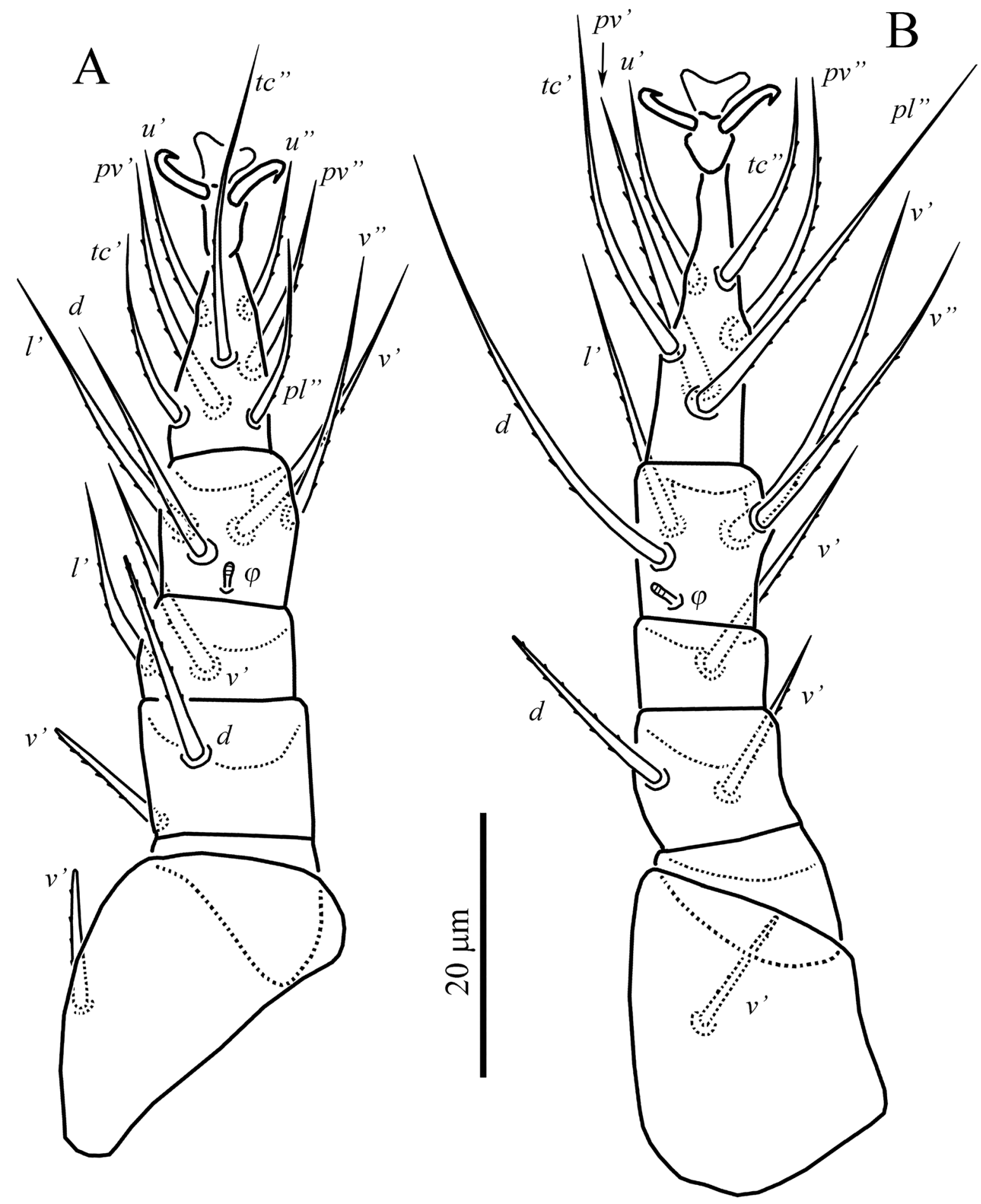

Fig. 9. Bochkovlaster variabilis gen.n. and sp.n., non-phoretic female: A-right leg III in dorsal view, B-right leg IV in dorsal view.

\section{Key to genera of Pygmephoridae}

(based on females, after Khaustov et al. 2019)

1. Legs I 5-segmented (tibia and tarsus separated).....

— Legs I 4-segmented (tibia and tarsus fused) ...
2. Setae $e$ absent 3

- Setae $e$ present 6

3. Prodorsum with one or three pairs of simple setae (excluding trichobothria)

\section{4}

- Prodorsum with two pairs of simple setae (excluding trichobothria)

Parasiteroptes Livshits, Mitrofanov and Sharonov, 1986 




Fig. 10. DIC micrographs of Bochkovlaster variabilis gen.n. and sp.n., phoretic female: A-prosoma in dorsal view, $\mathrm{B}$ - prosoma in ventral view, C - hysterosoma in dorsal view, D-hysterosoma in ventral view, E-tracheal trunks and pharyngeal pumps; non-phoretic female: F-pharyngeal pumps.

4. Prodorsum with three pairs of simple setae (excluding trichobothria).... 5 - Prodorsum with one pair of simple setae (excluding trichobothria)... (non-phoretic form)
5. Setae $4 a$ present, $4 c$ absent, body oval Krczaldania Sasa, 1961 - Setae $4 a$ absent, $4 c$ present, body fusiform..... ................................ Siteroptes Amerling, 1861

6. Setae $h_{2}$ present 8

- Setae $h_{2}$ absent 7 


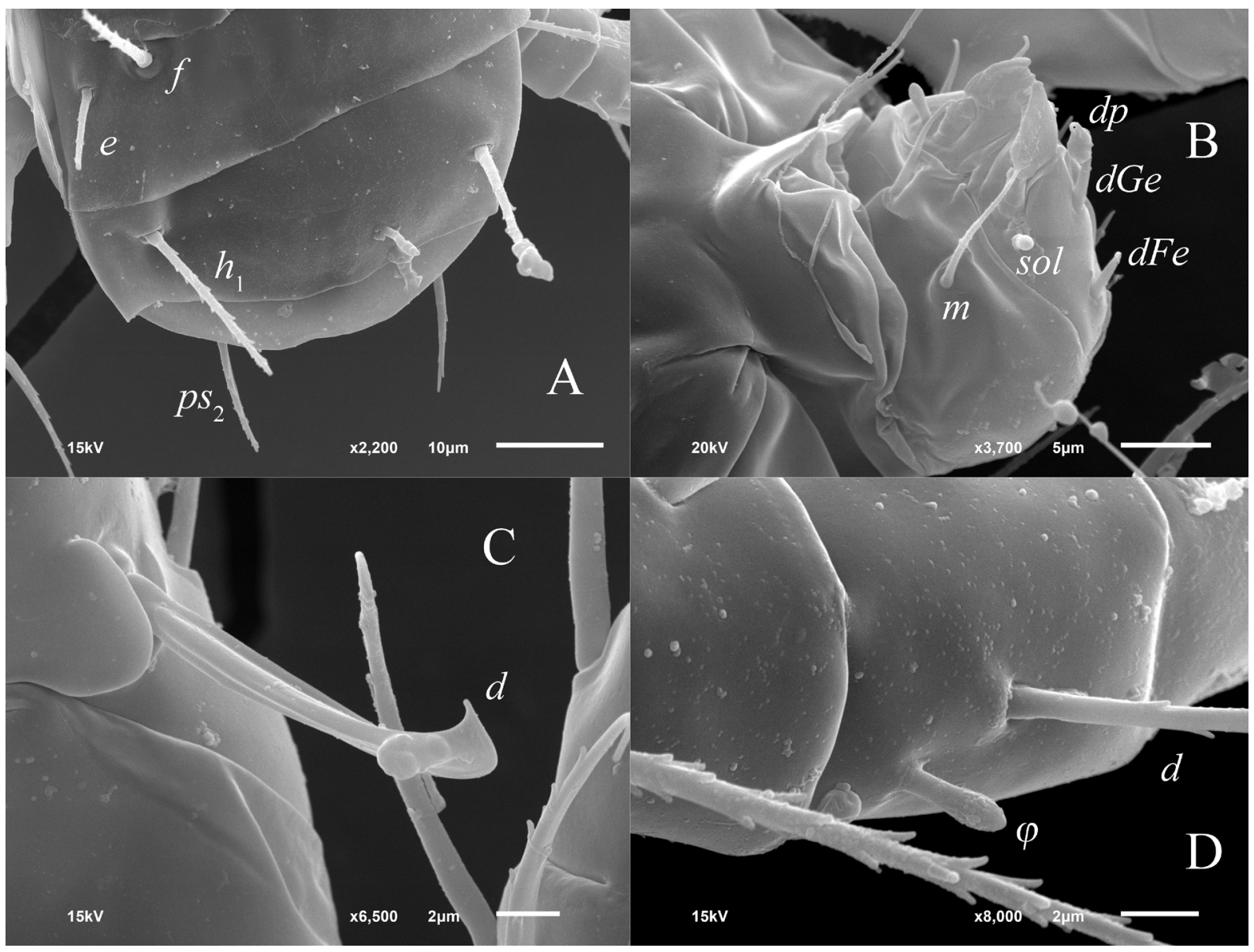

Fig. 11. SEM micrographs of Bochkovlaster variabilis gen.n. and sp.n., phoretic female: A-opisthosoma in dorsal view, B - gnathosoma in ventrolateral view, C - modified seta D of femur I, D — tibia III in dorsal view.

7. Body fusiform, genua II and III with one seta each. Metasiteroptes Cross, 1965

- Body oval, genu II with three setae, genu III with two seta. Bochkovlaster gen. n. (non-phoretic form)

8. Prodorsum with three pairs of simple setae (excluding trichobothria) 9

- Prodorsum with two pairs of simple setae (excluding trichobothria).... Ultrasiteroptes Livshits, Mitrofanov and Sharonov, 1986 9. Cupules im present, postpalpal setae present, setae $1 b$ usually bifurcate, coxal fields II with two pairs of setae .. 10

- Cupules im absent, postpalpal setae absent, setae $1 b$ not bifurcate, coxal fields II usually with three pairs of setae ......... Pediculaster Vitzthum, 1931 (non-phoretic form)

10. Coxal fields I with two pairs of setae ....... Sevastianoviella Livshits, Mitrofanov and Sharonov, 1986 - Coxal fields I with three pairs of setae ...... Neositeroptes Livshits, Mitrofanov and Sharonov, 1986 11. Coxal fields II with three pairs of setae..... 12
- Coxal fields II with two pairs of setae ....... 18 12. Setae $v$ ' of femur and $p l$ " of tarsus of leg IV not sword-like, claw of tibiotarsus I usually not very large, not striated. 13

- Setae $v$ ' of femur and $p l$ " of tarsus of leg IV sword-like, claw of tibiotarsus I very large, striated, associated with small mammals

Pygmephorus Kramer, 1877

13. Stigmata usually oval or round, sometimes with chambers, not long and narrow 14

- Stigmata long and narrow Luciaphorus Mahunka, 1981

14. Tibiotarsus I with claw 15

- Tibiotarsus I without claw Microdispodides Vitzthum, 1914

15. Seta $d$ of femur I modified 16 - Seta $d$ of femur I not modified . Pseudoluciaphorus Khaustov et al., 2019 16. Setae $l$ " of femur I not modified and not similar in shape with $d$ of femur I 17

- Setae l" of femur I spine-like, similar in shape with $d$ of femur I ......... Mahunkania Rack, 1972 


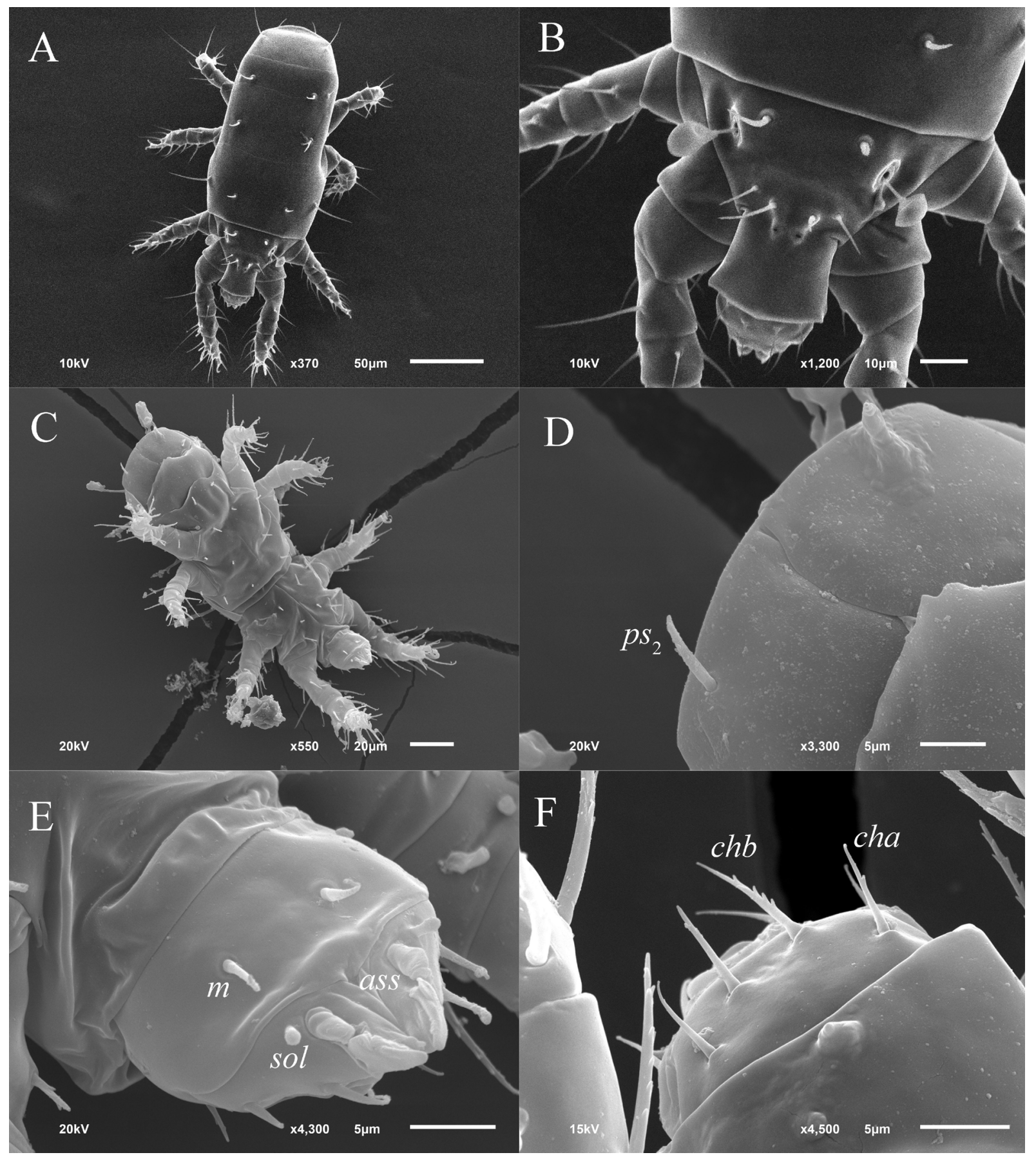

Fig. 12. SEM micrographs of Bochkovlaster variabilis gen. n. and sp.n., non-phoretic female: A—general view dorsally, $\mathrm{B}$ - prosoma in dorsal view, C-general view ventrally, D - pseudanal segment in ventral view, E-gnathosoma in ventral view; phoretic female: F-gnathosoma in dorsal view.

17. Setae $d$ of femur I spatulate, longer than width of femur I Pediculaster Vitzthum, 1931 (phoretic form) (part)

- Setae $d$ of femur I blade-like, shorter than width of femur I ........... Propygmephorus Cross, 1974 18. Coxal fields I with two pairs of setae ....... 19 - Coxal fields I with one or three pairs of setae
19. Prodorsum with three pairs of simple setae (excluding trichobothria) 20 - Prodorsum with two pairs of simple setae (excluding trichobothria) ........... Sasadania Kurosa, 1989 20. Setae $d$ of femur I not modified ............... 21

- Setae $d$ of femur I spatulate 22

21. Trichobothria present Dudichiana Mahunka, 1970 
- Trichobothria absent ...... Asensilla Rack, 1974

22. Tarsus II with four modified, spine-like setae Pygmephoroides Mahunka and Fain, 1989

- Tarsus II without spine-like setae

Pediculaster Vitzthum, 1931

(phoretic form) (part)

23. Coxal fields I with three pairs of setae .... 24

- Coxal fields I with one pair of setae Geotrupophorus Mahunka, 1970

24. Tarsi II and III with six setae each, trichobothria present 25

- Tarsi II and III with only four setae each ( $t c$ ' and $p l$ " absent), trichobothria absent

Micropygme-

phorus Khaustov, Hugo-Coetzee and Ermilov, 2017

25 . Setae $d$ of femur I longer than width of femur I 26

- Setae $d$ of femur I shorter than width of femur I 31

26. Prodorsum with three pairs of simple setae (excluding trichobothria) ............................ 28

- Prodorsum with two pairs of simple setae (excluding trichobothria) ................................. 27

27. Pseudanal segment distinctly narrowed and elongate posteriorly

Pediculitopsis Mahunka, 1970

(phoretic form)

- Pseudanal segment of normal shape, evenly rounded posteriorly

Apediculaster Rahiminejad and Hajiqanbar, 2016

28. Setae $h_{2}$ present 30

- Setae $h_{2}$ absent 29

29. Body fusiform, genua II and III with one seta each Brasilopsis Mahunka, 1975 (probably phoretic form of Metasiteroptes)

- Body oval, genua II with three setae, genu III with two seta Bochkovlaster gen. n. (phoretic form)

30. Leg IV distinctly shorter than leg III, tarsus IV short, with three very long, whip-like setae ........ Acarothorectes Cross, 1965

- Leg IV not shorter than leg III, tarsus IV not short, sometimes with only one whip-like setae tc' ...................... Pediculaster Vitzthum, 1931 (phoretic form) (part)

31. Empodia on tarsi II-IV present .............. 32 - Empodia on tarsi II-IV absent ..... Mesopotamiophorus Sevastianov and Zahida A1 Douri, 1991

32. Genu I with one or two setae, genu IV without setae 33

- Genu I with three or four setae, genu IV with one seta 34
33. Tibiotarsus I with two solenidia, setae $d$ of femur I hook-like, two pairs of pseudanal setae, setae $4 a$ and $4 c$ absent ... Elattoma Mahunka, 1969 - Tibiotarsus I with four solenidia, setae $d$ of femur I spatulate, three pairs of pseudanal setae, setae $4 a$ and $4 c$ present ........... Spatulaphorus Rack, 1993 34. Lateral surfaces of tibiotarsus I without slit-like structures, most setae of anterior and posterior sternal plates not modified .......................... 35 - Lateral surfaces of tibiotarsus I with slit-like structures, most setae of anterior and posterior sternal plates spine-like ...... Strephocheir Mahunka, 1983 35. Stigmata oval, unguinal setae $(u)$ of tibiotarsus I present as modified structure opposing to tarsal claw 36

- Stigmata long and narrow, unguinal setae $(u)$ of tibiotarsus I absent

Parapediculaster Khaustov, 2015

36. Subcapitular setae $m$ present, setae $2 b$ not bifurcate ................................................. 37 - Subcapitular setae $m$ absent, setae $2 b$ bifurcate .................................. Metapygmephorellus Rahiminejad, Hajiqanbar and Khaustov, 2015 37. Genu I with four setae, genu II with three setae 38

- Genu I with three setae, genu II with two setae ....... Pseudopygmephorellus Khaustov, 2008 38. Cupules im present, empodia on tarsi II-II rounded distally, claw on tibiotarsus I situated dorsally .... Pygmephorellus Cross and Moser, 1971 - Cupules im absent, empodia on tarsi II-II pointed distally, claw on tibiotarsus I twisted ventrally Cerattoma Mahunka, 1972

\section{DISCUSSION}

The new genus is characterized by a combination of apomorphic and plesiomorphic characters. Most of the apomorphic characters are losses of structures (cupules ia and im absent; setae $h_{2}, p s_{1}$ and $p s_{3}$ absent; absence of main tracheal trunks in non-phoretic female), except for the presence of an unusual dorsal projection on the palpal femorogenu in phoretic female (Figs. 10A, 11B). Similar structures have never been recorded in other pygmephorid mites. However, this structure is present in the sister-family Microdispidae, e.g., in the genera Punicodoxa Mahunka, 1978 and Sidorchukdispus Khaustov et al., 2019 (Khaustov et al. 2018, 2019a). Some plesiomorphic characters are also unique. Phoretic female of Bochkovlaster retains an unmodified tarsal claw and unguinal setae on tarsus I-these structures are almost identical in 


\section{A.A. Khaustov}

non-phoretic female. Moreover, unmodified unguinal setae on tarsus I are unknown in all described pygmephorid genera with fused tibia and tarsus I. Another unique plesiomorphic character is the retainment of articulation between basi- and telofemur of leg IV. Probably in all pygmephoroid mites, femur IV is separated into basi- and telofemur. However, these leg segments are always tightly fused with only a thin line separating them. In contrast to this condition, in Bochkovlaster, basi- and telofemur of leg IV are clearly separated ventrally by a soft cuticle, similar to the articulations between femur and genu.

The differences between phoretic and nonphoretic females are not as distinct as in the sister genus Pediculaster. In Pediculaster, phoretic female is usually much stronger sclerotized, tarsal claw and unguinal setae on tibiotarsus I are always modified. In Bochkovdispus, on the other hand, phoretic female is poorly sclerotized; and the tarsal claw, along with unguinal setae on tibiotarsus I, are not modified. Most likely, female dimorphism in Bochkovdispus is most plesiomorpnic among all pygmephorid mites.

\section{ACKNOWLEDGEMENTS}

I thank A.N. Bobylev and A.A. Gubin (Tyumen State University, Tyumen, Russia) for SEM micrographs.

\section{REFERENCES}

Camerik, A.M., de Lillo, E. and Lalkhan, C. 2006. The neotype of Pediculaster mesembrinae (Canestrini, 1881) (Acari: Siteroptidae) and the description of all life stages. International Journal of Acarology, 32 (1): 45-67.

Cross, E.A. 1965. The generic relationships of the family Pyemotidae (Acarina, Trombidiformes). The University of Kansas Science Bulletin, 45: 29-215.

Grandjean, F. 1944. Observations sur les Acariens de la famille des Stigmaeidae. Archives des Sciences Physiques et Naturelles, 26: 103-131.
Grandjean, F. 1947. L'origine pileuse des mors et la chaetotaxie de la mandibule chez les Acariens actinochitineux. Comptes rendus des Séances de l'Academie des Sciences, 224: 1251-1254.

Kaliszewski, M., Athias-Binche, F. and Lindquist, E.E. 1995. Parasitism and parasitoidism in Tarsonemina (Acari: Heterostigmata) and evolutionary considerations. Advances in Parasitology, 35: 335-367.

Khaustov, A.A. 2004. Mites of the family Neopygmephoridae Cross, 1965 stat.n. and their position in Heterostigmata. In: Y.S. Balashov (Ed.). Proceedings of VIII Russian Acarological Conference, St.-Petersburg. Zoological Institute of RAS, St.Petersburg, 137 pp. [In Russian]

Khaustov, A.A. 2008. Mites of the family Scutacaridae of Eastern Palaearctic. Akademperiodyka, Kiev, $291 \mathrm{pp}$.

Khaustov, A.A., Hugo-Coetzee, E.A. and Ermilov, S.G. 2018. New taxa of the family Microdispidae (Acari: Heterostigmata) associated with Trinervitermes trinervoides (Sjostedt) (Isoptera: Termitidae) from South Africa. International Journal of Acarology, 44: 218-226.

Khaustov, A.A., Hugo-Coetzee, E.A. and Ermilov, S.G. 2019a. A new genus and species of the family Microdispidae (Acari: Heterostigmata) associated with Trinervitermes trinervoides (Sjöstedt) (Isoptera: Termitidae) from South Africa. Zootaxa, 4647: 104-4114.

Khaustov, A.A., Hugo-Coetzee, E.A. and Ermilov S.G. 2019b. A new genus, new species and a new record of the family Pygmephoridae (Acari: Heterostigmata) associated with Microcerotermes-parvus (Haviland) (Isoptera: Termitidae) from South Africa. Systematic \& Applied Acarology, 24 (10), 1881-1892.

Lindquist, E.E. 1986. The world genera of Tarsonemidae (Acari: Heterostigmata): a morphological, phylogenetic, and systematic revision, with a reclassification of family-group taxa in the Heterostigmata. Memoirs of the Entomological Society of Canada, 118: 1-517. 